\title{
Not all adrenal incidentalomas require biochemical testing to exclude pheochromocytoma: Mayo clinic experience and a meta- analysis
}

\author{
Lucinda M. Gruber ${ }^{1 \#}$, Veljko Strajina ${ }^{2 \#}$, Irina Bancos ${ }^{1}$, M. Hassan Murad ${ }^{3}$, Benzon M. Dy ${ }^{2}$, William F. \\ Young, ${ }^{1}$, David R. Farley², Melanie L. Lyden ${ }^{2}$, Geoffrey B. Thompson', Travis J. McKenzie ${ }^{2}$ \\ ${ }^{1}$ Division of Endocrinology, Metabolism, Nutrition \& Diabetes, ${ }^{2}$ Department of Surgery, ${ }^{3}$ Evidence Based Practice Center, Robert D. and Patricia E. \\ Kern Center for the Science of Health Care Delivery, Mayo Clinic, Rochester, MN, USA \\ Contributions: (I) Conception and design: V Strajina, LM Gruber, I Bancos, TJ McKenzie; (II) Administrative support: I Bancos, MH Murad; (III) \\ Provision of study materials or patients: V Strajina, LM Gruber, I Bancos, BM Dy, DR Farley, ML Lyden, GB Thompson, TJ McKenzie; (IV) \\ Collection and assembly of data: V Strajina, LM Gruber; (V) Data analysis and interpretation: V Strajina, LM Gruber, I Bancos, MH Murad, TJ \\ McKenzie; (VI) Manuscript writing: All authors; (VII) Final approval of manuscript: All authors. \\ "These authors contributed equally to this work. \\ Correspondence to: Travis J. McKenzie, MD. Department of Surgery, Mayo Clinic, 200 First St SW, Rochester, MN 55905, USA. \\ Email: Mckenzie.Travis@mayo.edu; Irina Bancos, MD. Division of Endocrinology, Metabolism, Nutrition \& Diabetes, Mayo Clinic, 200 First St \\ SW, Rochester, MN 55905, USA. Email: Bancos.Irina@mayo.edu.
}

Background Excluding a pheochromocytoma is important when a patient presents with an incidentally discovered adrenal mass. However, biochemical testing for pheochromocytoma can be cumbersome, time consuming, or falsely positive. Our objective was to determine if unenhanced computed tomography (CT) imaging alone can be used to rule out pheochromocytoma.

Methods: We performed a retrospective study of all patients with a pathologically confirmed pheochromocytoma and unenhanced CT imaging who were treated at the Mayo Clinic between 1998 and 2016. Additionally, we performed a systematic review and meta-analysis of original studies published after 2005 with patients who had adrenal masses, more than 10 patients with pheochromocytomas, and reported attenuation on unenhanced CT imaging in Hounsfield units (HU).

Results: In the Mayo cohort, we identified 186 patients and 199 pheochromocytomas with unenhanced CT imaging. The mean unenhanced CT attenuation was 35 \pm HU (range, 15-62), and only 15 tumors had attenuation $\leq 20 \mathrm{HU}$. The systematic review identified 26 studies (1,217 tumors), and 23 studies provided a mean unenhanced CT attenuation. The overall mean unenhanced CT attenuation across the studies was 35.6 HU (95\% CI, 22.0-49.1 HU). A cutoff of >10 HU had a 100\% sensitivity (95\% CI, 1.00-1.00) for pheochromocytoma with low heterogeneity between the 21 qualified studies $\left(\mathrm{I}^{2}=0 \%\right)$. Sensitivity for pheochromocytoma was $100 \%$ and $99 \%$ for an unenhanced CT attenuation cutoff of $>15$ and $>20$ HU.

Conclusions: Biochemical testing may not be required to exclude pheochromocytoma if an incidental adrenal mass has low attenuation $(<10 \mathrm{HU})$ on unenhanced CT images.

Keywords: Pheochromocytoma; computed tomography (CT); Hounsfield units (HU); diagnosis

Submitted Jan 24, 2020. Accepted for publication Feb 14, 2020.

doi: $10.21037 /$ gs.2020.03.04

View this article at: http://dx.doi.org/10.21037/gs.2020.03.04 


\section{Introduction}

Biochemical exclusion of a catecholamine-producing pheochromocytoma is often recommended for all adrenal incidentalomas (1-3). There have been reports of pheochromocytomas mimicking hypodense adrenal adenomas $(4,5)$. Different tests are used to rule out a catecholamine-secreting pheochromocytoma, including 24-h urine fractionated metanephrines and catecholamines, as well as plasma fractionated metanephrines. The 24-h urine collection is cumbersome and may be performed incorrectly (6). Measuring plasma fractionated metanephrines can avoid the cumbersome 24-h urine collection; however, a false positive rate as high as $15 \%$ has been reported $(7,8)$. The question has been raised if the biochemical evaluation for pheochromocytoma can be omitted based on the imaging phenotype of the adrenal mass, resulting in the reduction of unnecessary testing, cost, and potential anxiety or overtreatment $(5,9,10)$. Furthermore, general surgeons can evaluate patients with an indication for abdominal surgery and a newly discovered adrenal mass. Exclusion of a catecholamine-producing pheochromocytoma based on imaging findings alone would simplify patient management and expedite operative treatment in this scenario.

The primary aim of our study was to determine the range of unenhanced attenuation for pathologically proven pheochromocytoma on computed tomography (CT) by combining a systematic review with a large cohort of patients treated at the Mayo Clinic. Finally, this would be used to determine a highly sensitive cutoff value of unenhanced attenuation that can be used to identify adrenal masses not requiring biochemical testing for pheochromocytoma.

\section{Methods}

\section{Retrospective review}

All patients with a pathologically confirmed pheochromocytoma treated at the Mayo Clinic between 1998 and 2016 were identified. Patients without unenhanced CT images were excluded. The images and radiology reports were reviewed. The axial cut with the greatest diameter of the tumor was identified and was considered to be the region of interest (ROI). The appearance of the mass was qualitatively assessed as either heterogeneous or homogeneous, and ROI was specifically selected in order to avoid inclusion of calcifications, which would result in increased measured attenuation. The average unenhanced attenuation of the ROI was measured within the greatest possible area not including calcifications or tumor periphery.

The study was approved by the Mayo Clinic Institutional Review Board (ID 14-008336) and a waiver of the requirement to obtain informed consent from the study subjects was approved considering the minimal risk of the study.

\section{Systematic review and meta-analysis}

\section{Eligibility criteria}

Studies meeting the following criteria were included in the review: original study, published after 2005, including patients with an adrenal nodule/mass and at least 10 patients with pheochromocytoma, reporting unenhanced attenuation of the adrenal tumor, written in English. Pheochromocytoma diagnosis was considered to be conclusive if it was based either on pathological findings or biochemical testing (24-h urine or plasma fractionated metanephrines/catecholamines at least 3 times higher than the upper limits of the reference ranges in a patient with an adrenal mass).

\section{Data sources and search strategies}

A comprehensive search of several databases using any language was conducted from January $1^{\text {st }}, 2005$ to May $30^{\text {th }}, 2018$. The databases included MEDLINE Epub Ahead of Print, Medline In-Process \& Other NonIndexed Citations, MEDLINE, EMBASE, Cochrane Central Register of Controlled Trials, Cochrane Database of Systematic Reviews, and Scopus. The search strategy was designed and conducted by a medical reference librarian with input from the study's principal investigator. Controlled vocabulary supplemented with keywords was used to search for studies using unenhanced CT for exclusion of a pheochromocytoma in humans. The actual strategy is provided in the appendix.

\section{Methodological quality assessment}

The quality of studies included in the meta-analysis was rated using QUADAS-2 scale (http://www.quadas.org). The risk of bias was rated in four domains: (I) patient selection; (II) interpretation of the index test; (III) reference standard; (IV) flow and timing. Concerns regarding applicability were assessed in the first three domains. The risk of bias and applicability was assessed as high, low or uncertain. The 


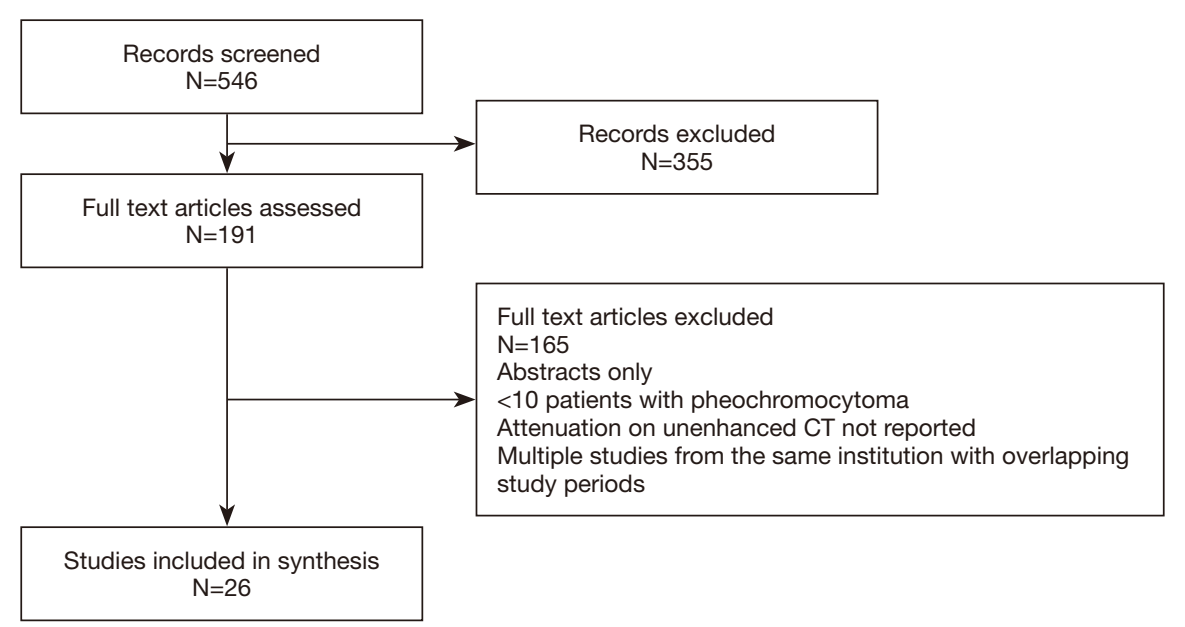

Figure 1 Flowchart of study assessment. CT, computed tomography.

studies were assessed independently by two reviewers, and their assessments were reconciled by a third reviewer.

\section{Data synthesis}

The studies were reviewed and the data extracted independently by two reviewers. Conflicts were resolved by consensus. Descriptive statistics of imaging characteristics including unenhanced CT attenuation measured in Hounsfield units (HU) and size were calculated. Randomeffect models meta-analysis was then used to estimate the pooled sensitivity and $95 \%$ confidence intervals (CIs) for the diagnosis of pheochromocytoma with different cutoffs of unenhanced attenuation: $>10,>15$ and $>20 \mathrm{HU}$. Sensitivity was defined as a proportion of patients with pheochromocytoma who had a positive test out of all patients with pheochromocytoma. Variance of proportions was stabilized using the Freeman Turkey double arcsine method (11). Weighted mean HU value was pooled from all pheochromocytomas across studies. $\mathrm{I}^{2}$ statistic was used to estimate heterogeneity. Analysis was conducted using STATA software package (StataCorp. 2017. Stata Statistical Software: Release 15. College Station, TX, USA: StataCorp LLC).

\section{Results}

\section{Retrospective review}

We identified 439 pathologically confirmed pheochromocytomas from the Mayo Clinic over the study period. Unenhanced CTs were available for 186 patients and a total of 199 tumors (13 bilateral). Mean tumor diameter was $38 \pm 22$ (range, 12-150) $\mathrm{mm} ; 124$ tumors were $\leq 40 \mathrm{~mm}$ in diameter. Most tumors were homogenous on non-contrast phase CT $(n=136,68 \%)$. For the entire cohort, mean unenhanced CT attenuation was $35 \pm 9 \mathrm{HU}$ (range, 15-62). Overall, only 15 tumors (8\%) had an unenhanced CT attenuation $\leq 20 \mathrm{HU}$ with $50 \%$ of these having attenuation measured at 19 or $20 \mathrm{HU}$; 8 tumors $(53 \%)$ had a heterogeneous appearance. A single pheochromocytoma with $\mathrm{CT}$ attenuation of $15 \mathrm{HU}$ had a significant cystic component. In the subgroup of homogenous tumors $\leq 40 \mathrm{~mm}(\mathrm{n}=115)$, mean CT attenuation was $36 \pm 8$ (range, 17-58) HU.

\section{Systematic review and meta-analysis}

The initial search identified 546 studies; after screening, full text evaluation was performed for 191 studies. As indicated in Figure 1, 165 studies were excluded. A total of 26 studies (1,217 tumors with unenhanced CT attenuation reported) were included in this systematic review, including the present cohort (Table 1) $(5,9,12-32)$. Twenty-three studies provided mean unenhanced density of the tumor with overall mean unenhanced CT attenuation of $35.6 \mathrm{HU}(95 \%$ CI, 22.0-49.1 HU), 21 studies (1,029 tumors) provided sufficient data to calculate the sensitivity for cutoff of $>10 \mathrm{HU}, 11$ studies (468 tumors) for cutoff of $>15 \mathrm{HU}$ and 13 studies (400 tumors) for cutoff of $>20 \mathrm{HU}$. Heterogeneity among studies was low with $\mathrm{I}^{2}=0 \%$ for mean CT attenuation and for sensitivity of $>10$ and $>15 \mathrm{HU}$ cutoffs, and $\mathrm{I}^{2}=12 \%$ at a cutoff of $>20 \mathrm{HU}$. Overall sensitivities for pheochromocytoma were 100\% (95\% CI, $1.00-1.00), 100 \%$ (95\% CI, $1.00-1.00)$, and $99 \%$ (95\% 
Table 1 Studies included in systematic review and meta-analysis

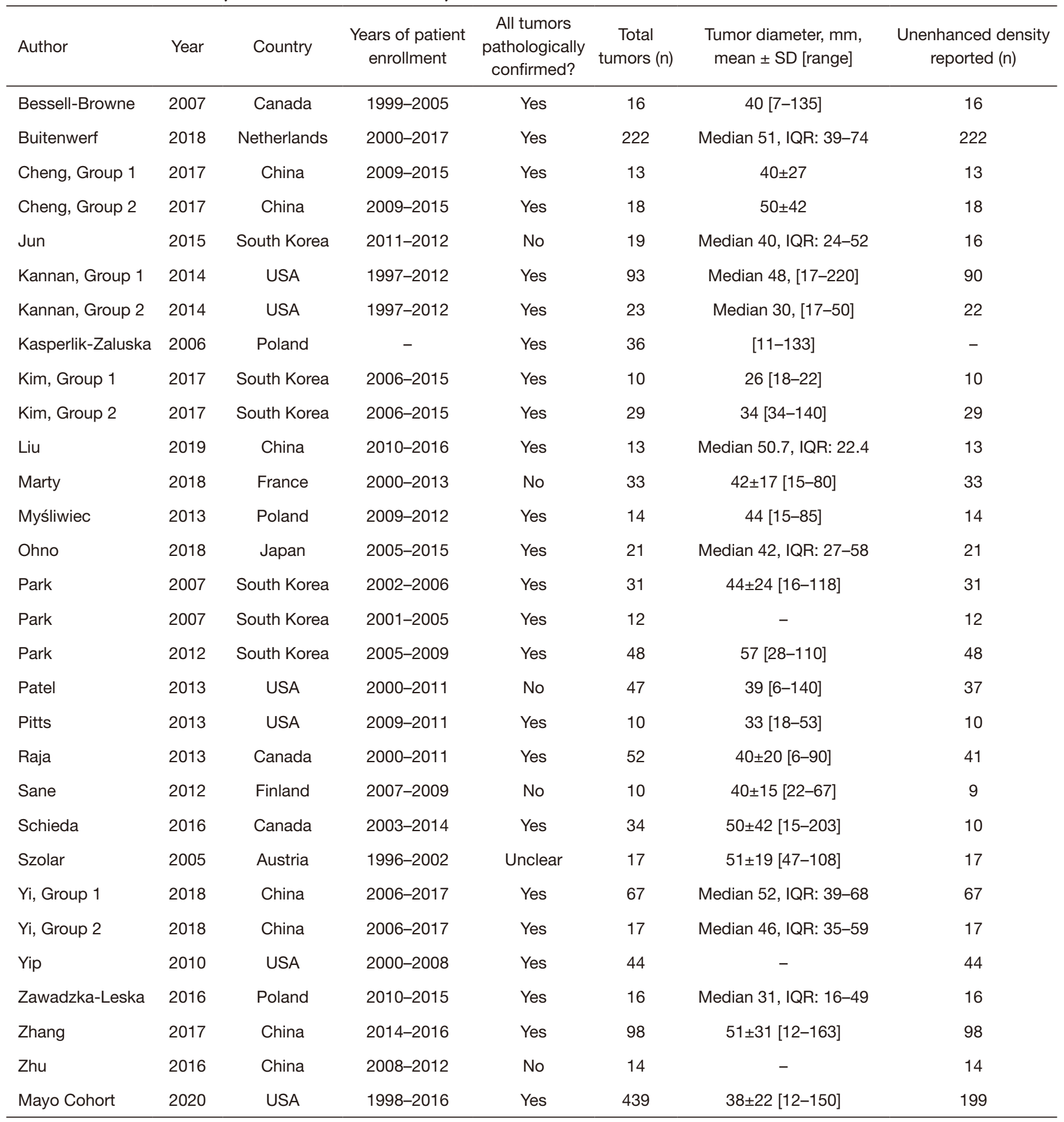




\begin{tabular}{|c|c|c|c|c|}
\hline Author & $\begin{array}{l}\text { Year } \\
\text { publication }\end{array}$ & $\begin{array}{l}n \\
\text { tumors } \\
>10 \mathrm{HU}\end{array}$ & $\begin{array}{l}\text { n } \\
\text { tumor with } \\
\text { noncontrast } C 1 \\
\text { (HU) available }\end{array}$ & ES $(95 \% \mathrm{Cl})$ \\
\hline Bessel-Browne & 2007 & 16 & 16 & $\longrightarrow 1.00(0.81,1.00$ \\
\hline Buitenwerf & 2018 & 221 & 222 & - $1.00(0.97,1.00$ \\
\hline Cheng Group 1 & 2017 & 13 & 13 & $\longrightarrow 1.00(0.77,1.00$ \\
\hline Cheng Group 2 & 2017 & 18 & 18 & $\longrightarrow 1.00(0.82,1.00$ \\
\hline Jun, J. H. & 2015 & 15 & 16 & $-0.94(0.72,0.99$ \\
\hline Kannan, S._group 2 & 22014 & 22 & 22 & $\rightarrow 1.00(0.85,1.00$ \\
\hline Kannan, S._group 1 & 12014 & 90 & 90 & $1.00(0.96,1.00$ \\
\hline Marty & 2018 & 33 & 33 & $\rightarrow 1.00(0.90,1.00$ \\
\hline Mysliwiec, Janusz & 2013 & 13 & 14 & $0.93(0.69,0.99$ \\
\hline Ohno, Youichi & 2018 & 21 & 21 & $\rightarrow 1.00(0.85,1.00$ \\
\hline Park BK & 2007 & 31 & 31 & $\rightarrow 1.00(0.89,1.00$ \\
\hline Park SH & 1007 & 12 & 12 & $\rightarrow 1.00(0.76 .1 .00$ \\
\hline Park SW & 2012 & 48 & 48 & $\rightarrow 1.00(0.93,1.00$ \\
\hline Patel & 2013 & 37 & 37 & $\rightarrow 1.00(0.91,1.00$ \\
\hline Pitts & 2013 & 10 & 10 & $\longrightarrow 1.00(0.72,1.00$ \\
\hline Raja & 2013 & 39 & 41 & $\rightarrow 0.95(0.84,0.99$ \\
\hline Sane & 2012 & 9 & 9 & $\longrightarrow 1.00(0.70,1.00$ \\
\hline Schieda & 2016 & 10 & 10 & $\longrightarrow 1.00(0.72,1.00$ \\
\hline Szolar & 2005 & 17 & 17 & $\longrightarrow 1.00(0.82,1.00$ \\
\hline Yip & 2010 & 43 & 44 & $\rightarrow 0.98(0.88,1.00$ \\
\hline Zhang & 2017 & 98 & 98 & $+1.00(0.96,1.00$ \\
\hline Zhu & 2016 & 14 & 14 & $\longrightarrow 1.00(0.78,1.00$ \\
\hline Mayo Clinic Cohort & 2020 & 199 & 199 & $+1.00(0.98,1.00$ \\
\hline Overall $\left(I^{2}=0.00 \%\right.$, & $P=0.81)$ & & & | $1.00(1.00,1.00$ \\
\hline-2 & & & 0 & 1 \\
\hline
\end{tabular}

Figure 2 Meta-analysis of the sensitivity for diagnosis of pheochromocytoma, unenhanced density on CT imaging $>10$ HU. CT, computed tomography; HU, Hounsfield units; CI, confidence interval.

CI, 0.96-1.00) for unenhanced CT attenuation cutoffs of $>10,>15$ and $>20 \mathrm{HU}$, respectively. Further results of the meta-analysis are presented in Figures 2-4. Using the crude numbers from the included studies, in 1,000 patients cutoffs of $>10,>15$ and $>20$ HU would lead to missing the diagnosis of 3, 5 and 44 pheochromocytomas, respectively.

\section{Methodological quality of included studies}

The methodological quality assessment of included studies is shown in Figure 5. Overall, risk of bias for domain 1 (patient selection) was low for 21 studies (81\%) since all studies had consecutive rather than a random sample, and most studies had pathologic confirmation of the diagnosis. The risk of bias was assessed as high for the majority of studies $(n=20,77 \%)$ for domain 2 (index test), since the persons interpreting the images were either not blinded to the diagnosis or this was not clearly stated, and/or there was no preset cutoff for unenhanced attenuation. The risk of bias for domain 3 (reference standard) was assessed as low for $26(100 \%)$ of the included studies. For domain 4 (flow and timing), the risk of bias was low for 18 (70\% of the studies). Studies with high risk of bias for this domain included patients who did not have non-contrast CT and exclusion of patients for unclear reasons or due to the presence of certain imaging characteristics. All studies were rated as low for concerns regarding applicability for domain 1 (patient selection), and 20 studies (77\%) were rated as low for domain 2 (index test). The studies were rated as high for concerns regarding applicability for this domain if the authors did not specify the number of patients with nonenhanced CT or if the range or cutoffs were not provided for unenhanced attenuation. Low concerns regarding applicability were assessed for the majority of the included studies ( $\mathrm{n}=25,96 \%)$ for domain 3 (reference standard).

\section{Certainty in the evidence}

The certainty in the reported sensitivity is at least moderate. Despite increased risk of bias in some QUADAS-2 domains, there were overall adequate ascertainment of the exposure and outcomes in these studies and limited concerns about heterogeneity or imprecision (33). 
Sensitivity of cutoff Hounsfield Unit>15 for diagnosis of pheochromocytoma

\begin{tabular}{|c|c|c|c|c|}
\hline Author & $\begin{array}{l}\text { Year } \\
\text { publication }\end{array}$ & ${\underset{\text { tumors }}{>15} \mathrm{HU}}^{n}$ & $\begin{array}{l}\text { n } \\
\text { tumor with } \\
\text { noncontrast CT } \\
\text { (HU) available }\end{array}$ & ES $(95 \% \mathrm{Cl})$ \\
\hline Cheng Group 1 & 2017 & 13 & 13 & $1.00(0.77,1.00)$ \\
\hline Cheng Group 2 & 2017 & 18 & 18 & $\rightarrow 1.00(0.82,1.00)$ \\
\hline Kannan, S._group 2 & 2014 & 22 & 22 & $-1.00(0.85,1.00)$ \\
\hline Kannan, S._group 1 & 2014 & 90 & 90 & $+1.00(0.96,1.00)$ \\
\hline Marty & 2018 & 33 & 33 & $\checkmark 1.00(0.90,1.00)$ \\
\hline Mysliwiec, Janusz & 2013 & 13 & 14 & $\rightarrow 0.93(0.69,0.99)$ \\
\hline Ohno, Youichi & 2018 & 21 & 21 & $1.00(0.85,1.00)$ \\
\hline Pitts & 2013 & 10 & 10 & $-1.00(0.72,1.00)$ \\
\hline Sane & 2012 & 9 & 9 & $\rightarrow 1.00(0.70,1.00)$ \\
\hline Schieda & 2016 & 10 & 10 & $-1.00(0.72,1.00)$ \\
\hline Szolar & 2005 & 17 & 17 & $1.00(0.82,1.00)$ \\
\hline Zhu & 2016 & 14 & 14 & $1.00(0.78,1.00)$ \\
\hline Mayo Clinic Cohort & 2020 & 198 & 199 & $0.99(0.97,1.00)$ \\
\hline \multicolumn{4}{|c|}{ Overall $\left(I^{2}=0.00 \%, P=0.98\right)$} & I $1.00(1.00,1.00)$ \\
\hline $\begin{array}{l}1 \\
-2\end{array}$ & -1 & & 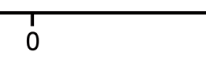 & \\
\hline
\end{tabular}

Figure 3 Meta-analysis of the sensitivity for diagnosis of pheochromocytoma, unenhanced density on CT imaging $>15$ HU. CT, computed tomography; HU, Hounsfield units; CI, confidence interval.

Sensitivity of cutoff Hounsfield Unit $>20$ for diagnosis of pheochromocytoma

\begin{tabular}{|c|c|c|c|c|}
\hline Author & $\begin{array}{l}\text { Year } \\
\text { publication }\end{array}$ & $\underbrace{n}_{>20} \mathrm{HU}$ & $\begin{array}{l}\text { n } \\
\text { tumor with } \\
\text { noncontrast CT } \\
\text { (HU) available }\end{array}$ & ES $(95 \% \mathrm{Cl})$ \\
\hline Bessel-Browne & 2007 & 16 & 16 & $1.00(0.81,1.00)$ \\
\hline Cheng Group 1 & 2017 & 13 & 13 & $\rightarrow 1.00(0.77,1.00)$ \\
\hline Cheng Group 2 & 2017 & 18 & 18 & $\rightarrow 1.00(0.82,1.00)$ \\
\hline Jun, J. H. & 2015 & 14 & $\longrightarrow$ & $0.88(0.64,0.97)$ \\
\hline Kannan, S._group 2 & 2014 & 22 & 22 & $-1.00(0.85,1.00)$ \\
\hline Mysliwiec, Juanusz & 2013 & 13 & 14 & $0.93(0.69,0.99)$ \\
\hline Park SH & 2007 & 12 & 12 & $\rightarrow 1.00(0.76,1.00)$ \\
\hline Park SW & 2012 & 48 & 48 & $\rightarrow 1.00(0.93,1.00)$ \\
\hline Pitts & 2013 & 10 & 10 & $\rightarrow 1.00(0.72,1.00)$ \\
\hline Sane & 2012 & 9 & 9 & $-1.00(0.70,1.00)$ \\
\hline Schieda & 2016 & 10 & 10 & $1.00(0.72,1.00)$ \\
\hline Szolar & 2005 & 17 & 17 & $\rightarrow 1.00(0.82,1.00)$ \\
\hline Zhu & 2016 & 14 & 14 & $\rightarrow 1.00(0.78,1.00)$ \\
\hline Mayo Clinic Cohort & 2020 & 184 & 199 & $\rightarrow 0.92(0.88,0.95)$ \\
\hline \multicolumn{4}{|c|}{ Overall $\left(I^{2}=11.66 \%, P=0.33\right)$} & $0.99(0.96,1.00)$ \\
\hline 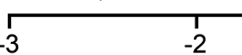 & -1 & & $\begin{array}{l}1 \\
0\end{array}$ & 12 \\
\hline
\end{tabular}

Figure 4 Meta-analysis of the sensitivity for diagnosis of pheochromocytoma, unenhanced density on CT imaging >20 HU. CT, computed tomography; HU, Hounsfield units; CI, confidence interval. 

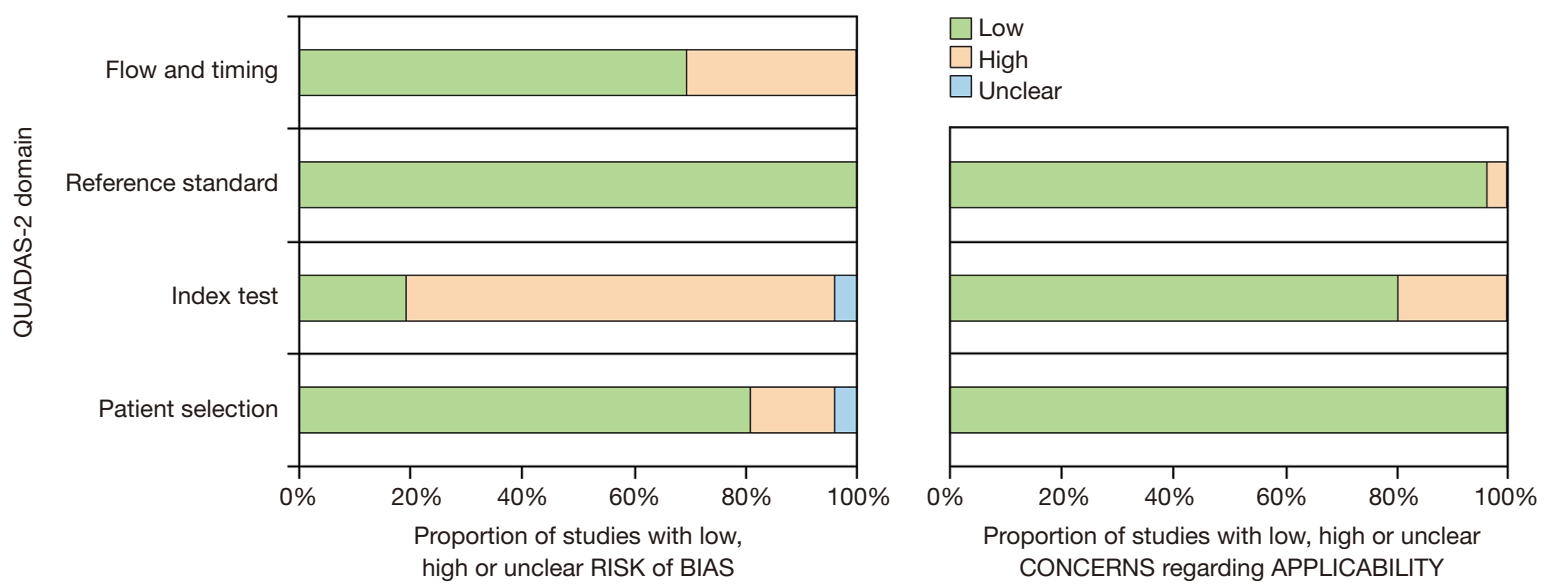

Figure 5 QUADAS-2 assessment of bias and applicability.

\section{Discussion}

Our data show that imaging alone can be sufficient to rule out pheochromocytoma in many patients. We suggest a cutoff of $<10 \mathrm{HU}$ on unenhanced CT to rule out a pheochromocytoma. Pheochromocytomas with unenhanced CT attenuation $\leq 20 \mathrm{HU}$ appear to be quite rare ( $4 \%$ of tumors). However, the majority of studies in our meta-analysis used a cutoff of $>10 \mathrm{HU}$ (19 studies, 963 tumors) and resulted in a pooled sensitivity of $100 \%$. The consequence of missing a pheochromocytoma diagnosis is also potentially catastrophic. Therefore, a conservative cutoff of $<10 \mathrm{HU}$ is reasonable.

Several recent studies have shown similar results. A multicenter retrospective study from the Netherlands ( $\mathrm{n}=222$ tumors) showed hypodense pheochromocytomas on CT imaging being exceedingly rare $(<0.5 \%)(13)$. Additionally, a multicenter study ( $\mathrm{n}=376$ tumors), which includes some of our cohort, showed only two tumors $(0.5 \%)$ with an unenhanced attenuation of $10 \mathrm{HU}$ and no tumors with $<10 \mathrm{HU}$ (34). A recent meta-analysis ( $\mathrm{n}=1,167$ tumors) also proposed a cutoff of $<10 \mathrm{HU}$ to rule out pheochromocytoma and showed this method is cost effective (35).

"Hypodense pheochromocytoma" is a poorly documented phenomenon. A study from 1987 (4) gives a pathologic description of lipid infiltration of a pheochromocytoma, however, no details regarding attenuation of the tumor were provided. Our cohort did not have any pheochromocytomas with an unenhanced $\mathrm{CT}$ attenuation of $<15 \mathrm{HU}$, even when heterogeneous masses were examined, and pheochromocytomas $\leq 20 \mathrm{HU}$ were rare $(8 \%)$, with about a half of such tumors $(53 \%)$ being heterogeneous. Only 3 pheochromocytomas with unenhanced CT attenuation $<10 \mathrm{HU}$ were identified in the systematic review. No potential explanations for this phenomenon were offered in the series by Jun et al. (5) or by Myśliwiec et al. (20). Buitenwerf et al. describe a single low attenuation tumor $(-4 \mathrm{HU})$ as an ACTH-secreting lesion causing Cushing syndrome, but without obvious necrosis, cystic parts or calcifications (13).

It is of concern that potential inclusion of hypodense areas of partially cystic or necrotic masses into ROI may result in a measurement below our proposed cutoffs, thus leading to false exclusion of a pheochromocytoma. However, even when heterogeneous masses from our cohort were included in analysis, the lowest unenhanced CT attenuation was $15 \mathrm{HU}$ in a predominantly cystic tumor. Therefore, it appears that the technique of measurement applied in our study can avoid the pitfall, and the unenhanced attenuation remains $>10 \mathrm{HU}$ even in such extreme cases. It should be pointed out that heterogeneity of the mass in our study was assessed qualitatively, as a visual impression of the observer, rather than using a particular algorithm. Caution should be exercised when approaching adrenal lesions with cystic components, calcifications or hypodense areas possibly associated with areas of necrosis or hemorrhage since these features make a lipid-rich adenoma unlikely and about $7 \%$ of cystic adrenal lesions can be associated with a pheochromocytoma (36).

There are certain limitations to our study. The majority of articles included in this review are retrospective single institution series, with relatively small numbers of patients. The data were not reported consistently across the 
studies, since their objectives varied and only a minority of studies focused on the hypothesis presented in our study. Two studies including a total of 80 tumors $(16,31)$ did not clearly report if all patients had unenhanced CT performed. An important but unlikely source of bias would be utilization of unenhanced CT attenuation for exclusion of pheochromocytoma during study enrollment periods. This would then falsely decrease the proportion of hypodense pheochromocytoma, as those tumors would go undiagnosed. This scenario seems very unlikely and to our knowledge this approach to biochemical testing for pheochromocytoma in patients with adrenal masses was not a routine part of clinical practice at the Mayo Clinic during the study period.

\section{Conclusions}

Patients with an incidentally discovered adrenal mass do not require biochemical testing to exclude pheochromocytoma if the neoplasm has low attenuation $(<10 \mathrm{HU})$ on unenhanced CT images.

\section{Acknowledgments}

Funding: None.

\section{Footnote}

Conflicts of Interest: All authors have completed the ICMJE uniform disclosure form (available at http://dx.doi. org/10.21037/gs.2020.03.04). Dr. Bancos reports grants from HRA Pharma, other from ClinCor, other from Corcept, outside the submitted work. The other authors have no conflicts of interest to declare.

Ethical Statement: The authors are accountable for all aspects of the work in ensuring that questions related to the accuracy or integrity of any part of the work are appropriately investigated and resolved. The study was approved by the Mayo Clinic Institutional Review Board (ID 14-008336) and a waiver of the requirement to obtain informed consent from the study subjects was approved considering the minimal risk of the study.

Open Access Statement: This is an Open Access article distributed in accordance with the Creative Commons Attribution-NonCommercial-NoDerivs 4.0 International License (CC BY-NC-ND 4.0), which permits the non- commercial replication and distribution of the article with the strict proviso that no changes or edits are made and the original work is properly cited (including links to both the formal publication through the relevant DOI and the license). See: https://creativecommons.org/licenses/by-nc-nd/4.0/.

\section{References}

1. Zeiger MA, Siegelman SS, Hamrahian AH. Medical and surgical evaluation and treatment of adrenal incidentalomas. J Clin Endocrinol Metab 2011;96:2004-15.

2. Fassnacht $M$, Arlt W, Bancos I, et al. Management of adrenal incidentalomas: European Society of Endocrinology Clinical Practice Guideline in collaboration with the European Network for the Study of Adrenal Tumors. Eur J Endocrinol 2016;175:G1-34.

3. Zeiger MA, Thompson GB, Duh QY, et al. The American Association of Clinical Endocrinologists and American Association of Endocrine Surgeons medical guidelines for the management of adrenal incidentalomas. Endocr Pract 2009;15 Suppl 1:1-20.

4. Ramsay JA, Asa SL, van Nostrand AW, et al. Lipid degeneration in pheochromocytomas mimicking adrenal cortical tumors. Am J Surg Pathol 1987;11:480-6.

5. Jun JH, Ahn HJ, Lee SM, et al. Is preoperative biochemical testing for pheochromocytoma necessary for all adrenal incidentalomas? Medicine (Baltimore) 2015;94:e1948.

6. Mann SJ, Gerber LM. Estimation of 24-hour sodium excretion from spot urine samples. J Clin Hypertens (Greenwich) 2010;12:174-80.

7. Sawka AM, Jaeschke R, Singh RJ, et al. A comparison of biochemical tests for pheochromocytoma: measurement of fractionated plasma metanephrines compared with the combination of 24-hour urinary metanephrines and catecholamines. J Clin Endocrinol Metab 2003;88:553-8.

8. Sawka AM, Prebtani AP, Thabane L, et al. A systematic review of the literature examining the diagnostic efficacy of measurement of fractionated plasma free metanephrines in the biochemical diagnosis of pheochromocytoma. BMC Endocr Disord 2004;4:2.

9. Sane T, Schalin-Jäntti C, Raade M. Is biochemical screening for pheochromocytoma in adrenal incidentalomas expressing low unenhanced attenuation on computed tomography necessary? J Clin Endocrinol Metab 2012;97:2077-83.

10. Schalin-Jäntti C, Raade $M$, Hämäläinen E, et al. A 
5-year prospective follow-up study of lipid-rich adrenal incidentalomas: no tumor growth or development of hormonal hypersecretion. Endocrinol Metab (Seoul) 2015;30:481-7.

11. Barendregt JJ, Doi SA, Lee YY, et al. Meta-analysis of prevalence. J Epidemiol Community Health 2013;67:974-8.

12. Bessell-Browne R, O'Malley ME. CT of pheochromocytoma and paraganglioma: risk of adverse events with i.v. administration of nonionic contrast material. AJR Am J Roentgenol 2007;188:970-4.

13. Buitenwerf E, Korteweg T, Visser A, et al. Unenhanced CT imaging is highly sensitive to exclude pheochromocytoma: a multicenter study. Eur J Endocrinol 2018;178:431-7.

14. Cheng S, Wang X, Huang J, et al. The value of dualphase enhancement CT as a predictor of the preoperative preparation of adrenal pheochromocytoma. International Surgery 2017;102:318-23.

15. Kannan S, Purysko A, Faiman C, et al. Biochemical and radiological relationships in patients with pheochromocytoma: lessons from a case control study. Clin Endocrinol (Oxf) 2014;80:790-6.

16. Kasperlik-Zaluska AA, Roslonowska E, SlowinskaSrzednicka J, et al. 1,111 patients with adrenal incidentalomas observed at a single endocrinological center: incidence of chromaffin tumors. Ann N Y Acad Sci 2006;1073:38-46.

17. Kim DW, Yoon SK, Kim SH, et al. Assessment of clinical and radiologic differences between small and large adrenal pheochromocytomas. Clin Imaging 2017;43:153-7.

18. Liu T, Sun H, Zhang H, et al. Distinguishing adrenal adenomas from non-adenomas with multidetector CT: evaluation of percentage washout values at a short time delay triphasic enhanced CT. Br J Radiol 2019;92:20180429.

19. Marty M, Gaye D, Perez P, et al. Diagnostic accuracy of computed tomography to identify adenomas among adrenal incidentalomas in an endocrinological population. Eur J Endocrinol 2018;178:439-46.

20. Myśliwiec J, Siewko K, Zukowski L, et al. Pheochromocytoma--analysis of 15 consecutive cases from one centre. Endokrynol Pol 2013;64:192-6.

21. Ohno Y, Sone M, Taura D, et al. Evaluation of quantitative parameters for distinguishing pheochromocytoma from other adrenal tumors. Hypertens Res 2018;41:165-75.

22. Park BK, Kim CK, Kwon GY, et al. Re-evaluation of pheochromocytomas on delayed contrast-enhanced CT: washout enhancement and other imaging features. Eur Radiol 2007;17:2804-9.

23. Park SH, Kim MJ, Kim JH, et al. Differentiation of adrenal adenoma and nonadenoma in unenhanced CT: new optimal threshold value and the usefulness of size criteria for differentiation. Korean J Radiol 2007;8:328-35.

24. Park SW, Kim TN, Yoon JH, et al. The washout rate on the delayed CT image as a diagnostic tool for adrenal adenoma verified by pathology: a multicenter study. Int Urol Nephrol 2012;44:1397-402.

25. Patel J, Davenport MS, Cohan RH, et al. Can established CT attenuation and washout criteria for adrenal adenoma accurately exclude pheochromocytoma? AJR Am J Roentgenol 2013;201:122-7.

26. Pitts A, Ih G, Wei M, et al. Clinical utility of FDGPET for diagnosis of adrenal mass: a large single-center experience. Hormones (Athens) 2013;12:417-27.

27. Raja A, Leung K, Stamm M, et al. Multimodality imaging findings of pheochromocytoma with associated clinical and biochemical features in 53 patients with histologically confirmed tumors. AJR Am J Roentgenol 2013;201:825-33.

28. Schieda N, Alrashed A, Flood TA, et al. Comparison of quantitative MRI and CT washout analysis for differentiation of adrenal pheochromocytoma from adrenal adenoma. AJR Am J Roentgenol 2016;206:1141-8.

29. Szolar DH, Korobkin M, Reittner P, et al. Adrenocortical carcinomas and adrenal pheochromocytomas: mass and enhancement loss evaluation at delayed contrast-enhanced CT. Radiology 2005;234:479-85.

30. Yi X, Guan X, Zhang Y, et al. Radiomics improves efficiency for differentiating subclinical pheochromocytoma from lipid-poor adenoma: a predictive, preventive and personalized medical approach in adrenal incidentalomas. EPMA J 2018;9:421-9.

31. Yip L, Tublin ME, Falcone JA, et al. The adrenal mass: correlation of histopathology with imaging. Ann Surg Oncol 2010;17:846-52.

32. Zawadzka-Leska SK, Radziszewski M, Malec K, et al. Predictive value of chromogranin a in a diagnosis towards pheochromocytoma in adrenal incidentaloma. Acta Endocrinol (Buchar) 2016;12:437-42.

33. Schünemann HJ, Mustafa RA, Brozek J, et al. GRADE guidelines: 22. The GRADE approach for tests and strategies-from test accuracy to patient-important 
outcomes and recommendations. J Clin Epidemiol 2019;111:69-82.

34. Canu L, Van Hemert JAW, Kerstens MN, et al. CT characteristics of pheochromocytoma: relevance for the evaluation of adrenal incidentaloma. J Clin Endocrinol Metab 2019;104:312-8.

Cite this article as: Gruber LM, Strajina V, Bancos I, Murad MH, Dy BM, Young WF, Farley DR, Lyden ML, Thompson GB, McKenzie TJ. Not all adrenal incidentalomas require biochemical testing to exclude pheochromocytoma: Mayo clinic experience and a meta-analysis. Gland Surg 2020;9(2):362-371. doi: $10.21037 /$ gs.2020.03.04
35. Buitenwerf E, Berends AMA, van Asselt ADI, et al. Diagnostic accuracy of computed tomography to exclude pheochromocytoma: a systematic review, meta-analysis, and cost analysis. Mayo Clin Proc 2019;94:2040-52.

36. Erickson LA, Lloyd RV, Hartman R, et al. Cystic adrenal neoplasms. Cancer 2004;101:1537-44. 